\title{
Aortic root replacement with cryopreserved homograft for infective endocarditis in the modern North American opioid epidemic
}

\author{
Ibrahim Sultan, MD, Valentino Bianco, DO, MPH, Arman Kilic, MD, Danny Chu, MD, \\ Forozan Navid, MD, and Thomas G. Gleason, MD
}

\section{ABSTRACT}

Objective: To study mid-term survival in patients with infective endocarditis as a result of IV drug use undergoing aortic root replacement with cryopreserved aortic homograft.

Methods: Patients undergoing aortic root homograft replacement from 20112017 were studied retrospectively. Aortic root replacement was performed using a modified Bentall technique. Primary outcomes included both short-term and mid-term survival. Secondary outcomes included immediate postoperative complications.

Results: A total of 138 patients underwent cryopreserved homograft replacement of the aortic root for aortic root abscesses. Eighty-five patients $(61.6 \%)$ underwent reoperative sternotomy, and 12 patients $(8.7 \%)$ underwent second or third reoperative sternotomy. Sixty-seven $(48.5 \%)$ patients had severe aortic insufficiency preoperatively. Operative mortality was $12.3 \%$ (17 patients). Five patients $(3.6 \%)$ sustained a permanent stroke. Twenty-one patients $(15.2 \%)$ required dialysis for renal failure, and 21 patients $(15.2 \%)$ had complete heart block necessitating a permanent pacemaker. Estimated 5-year mortality for the cohort was $43 \%$.

Conclusions: Cryopreserved homograft replacement is a safe and desirable option for high-risk patients with infective endocarditis and aortic root abscess. Homograft accommodation for a widely debrided aortic annular bed provides a reasonable surgical strategy for patients needing aortic root replacement with annular abscess. (J Thorac Cardiovasc Surg 2019;157:45-50)

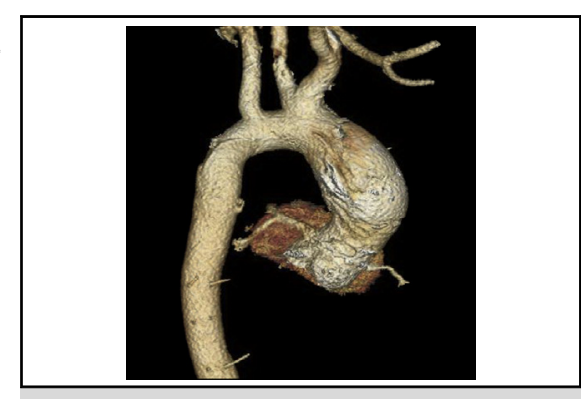

Computed tomography angiography in a 28-year-old male with intravenous drug abuse with an aortic root pseudoaneurysm.

\section{Central Message}

Cryopreserved homograft replacement is a safe and desirable surgical option for high-risk patients with infective endocarditis and aortic root abscess

\section{Perspective}

Owing to the current worsening problem of intravenous drug abuse in the United States, an ever-increasing patient population challenges cardiothoracic surgeons with extensive aortic root abscesses necessitating wide debridement and root replacement. Use of an aortic homograft may be a safe and reliable method for replacing the infected aortic root in this challenging cohort.

See Editorial Commentary page 51.
Infective endocarditis (IE) was first described by William Osler in 1885 . More than a century later, it continues to

\footnotetext{
From the Division of Cardiac Surgery, University of Pittsburgh and Heart and Vascular Institute, Univeristy of Pittsburgh Medical Center, Pittsburgh, Pa. Drs Sultan and Bianco contributed equally to this work as co-first authors.

Read at The American Association for Thoracic Surgery Aortic Symposium 2018, New York, New York, April 26-27, 2018.

Received for publication Feb 2, 2018; revisions received May 8, 2018; accepted for publication May 14, 2018; available ahead of print June 29, 2018.

Address for reprints: Ibrahim Sultan, MD, Division of Cardiac Surgery, 5200 Centre Ave, Suite 715, Pittsburgh, PA (E-mail: sultani@upmc.edu). $0022-5223 / \$ 36.00$

Copyright (C) 2018 by The American Association for Thoracic Surgery https://doi.org/10.1016/j.jtcvs.2018.05.050
}

be a complex illness, with an incidence ranging from 1.5 to 11.6 cases per 100,000 person-years, and even after the best medical and surgical management, it carries an inhospital mortality of $20 \%$ to $25 \%$. $^{1,2}$ State-of-the-art management of IE is best performed by a multidisciplinary team of surgeons, infectious disease specialists, cardiologists, psychologists, nurses, and social workers. ${ }^{3,4}$

Invasive IE of the aortic valve with associated aortic root abscess can be a surgical challenge, and reoperative mortality as high as $39 \%$ has been reported. ${ }^{5,6}$ Cryopreserved valved homografts have numerous advantages, including a favorable hemodynamic profile, low transvalvular gradients, low risk of thromboembolic events without the 


\section{Abbreviations and Acronyms}

AVR = Aortic valve replacement

COPD $=$ Chronic obstructive pulmonary disease

IE $=$ Infective endocarditis

IVDA $=$ Intravenous drug abuse

need for systemic anticoagulation, a potentially reduced risk of recurrent endocarditis, and, most importantly, greater versatility and flexibility for reconstruction of the aortic annulus and aortomitral continuity, allowing for more aggressive wide debridement of invasive infection-complete debridement being the sine qua non of surgical treatment of invasive aortic valve endocarditis. Given these advantages, cryopreserved aortic homografts are the ideal choice for surgical replacement of the aortic root in the setting of invasive disease. Annular invasion, abscess, fistula, septal defect, or prosthetic valve infection are the class I indications for the use of a homograft. ${ }^{7-9}$

Intravenous drug abuse (IVDA) continues to be a major public health crisis in the United States and is estimated to involve $2.6 \%$ of the population. IVDA substantially increases the risk of developing endocarditis to an incidence of 150 to 2000 cases per 100,000 person-years, compared with only 1.7 to 6.2 cases per 100,000 person-years in the general population. ${ }^{10-12}$ The demographic for developing endocarditis has also changed over the past decade, and multiple studies now reveal the population to be younger, whiter, and more female, with an increased incidence of $40 \%$ to $110 \%{ }^{1,10,13-15}$ In light of this national epidemic of IVDA-associated endocarditis and the paucity of available published data, we reviewed institutional outcomes for patients with aortic root abscess who underwent cryopreserved homograft replacement in the current era. For a point of reference, one of the largest and most-cited recent North American studies included 29 patients who underwent aortic root replacement with a homograft for endocarditis, demonstrating acceptable midterm survival. ${ }^{16}$

\section{METHODS}

The study cohort comprised patients undergoing homograft aortic root replacement for invasive aortic valve endocarditis due to IVDA at the University of Pittsburgh Medical Center between 2011 and 2017. Chart data from 138 patients were retrospectively extracted from a prospectively maintained cardiac surgical database. The center's Institutional Review Board approved the use of the database and extraction of data from it.

Cryopreserved valved homograft aortic root replacement was performed after aggressive and wide debridement. The homografts were implanted with a running or interrupted suture line using running 3-0 polypropylene. ${ }^{17}$ After appropriate sizing and trimming of the homograft, single interrupted 3-0 polypropylene sutures were placed circumferentially around the annulus, ensuring full-thickness bites of tissue. The use of braided sutures, Teflon pledgets, and any other foreign materials was avoided. Once sutures were passed through the homograft, the conduit was seated and secured by tying the knots in place. Alternatively, the entire conduit was sewn to the annulus with 3 separate running 2-0 polypropylene sutures beginning at each commissure. Coronary arteries were reimplanted in an orthotopic fashion.

Primary outcomes included both short-term and mid-term survival. Secondary outcomes included immediate postoperative complications. Descriptive statistics are presented as mean \pm standard deviation for continuous parametric variables and as percentage (frequency) for categorical variables. A Kaplan-Meier time-to-event plot was used to draw survival curves and calculate 5-year survival rates (Figure 1).

\section{RESULTS}

The study population consisted of predominantly male patients with a median age of 57.5 years (range, 2085 years). Forty-one cases $(29.7 \%$ ) were first-time cardiac surgeries, but the majority of the cases were reoperations (85 first reoperations [61.6\%] and 12 second or third reoperations $[8.7 \%])$. Comorbidities included diabetes $(29.7 \%)$, renal failure requiring dialysis $(10.9 \%)$, hypertension $(63 \%)$, history of cerebrovascular accident $(21.7 \%)$, chronic obstructive pulmonary disease $(10.9 \%)$, peripheral vascular disease $(23.9 \%)$, and heart failure within 2 weeks of surgery (30.4\%) (Table 1). All patients $(\mathrm{n}=138)$ had aortic root abscesses, and nearly one-half of the patients $(48.5 \%)$ had associated severe aortic regurgitation.

The operative 30-day mortality was $12.3 \%(\mathrm{n}=17)$. There was 1 intraoperative death. The mean cardiopulmonary bypass time was 233 minutes (range, 42-622 minutes), and the mean aortic cross-clamp time was 191 minutes (range, 20-400 minutes) (Table 2). The mean postoperative length of stay was 10 days (range, 0-127 days). Eleven patients $(8 \%)$ required reexploration for postoperative

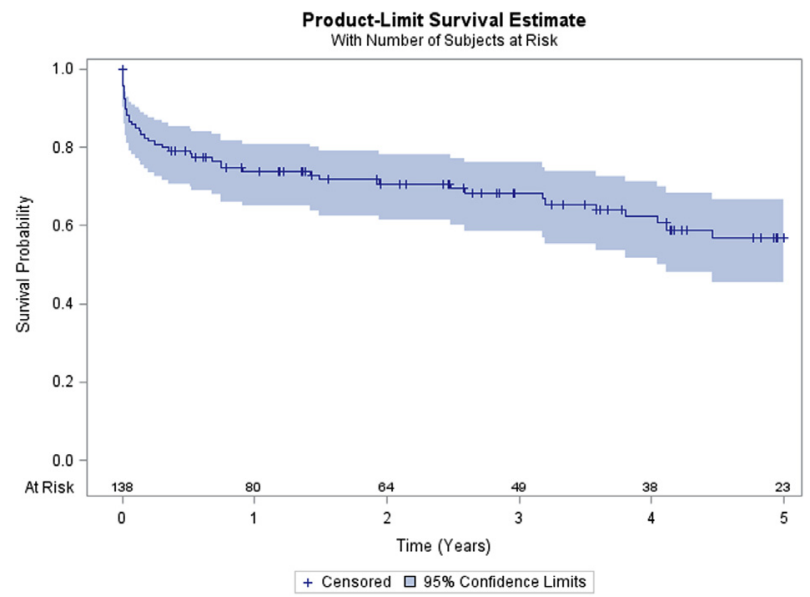

FIGURE 1. Survival curve of patients undergoing cryopreserved homograft replacement for aortic root abscess. 
TABLE 1. Preoperative characteristics of patients with invasive endocarditis undergoing cryopreserved homograft replacement

\begin{tabular}{lc}
\hline \multicolumn{1}{c}{ Characteristic } & Value \\
\hline Number of patients & 138 \\
Male sex, n (\%) & $104(75.4)$ \\
\hline Age, y, median (range) & $57.5(20.0-85.0)$ \\
History of intravenous drug use, n (\%) & $138(100)$ \\
Virgin sternotomy, n (\%) & $41(29.7)$ \\
First reoperation sternotomy, n (\%) & $85(61.6)$ \\
Second or more reoperation sternotomy, n (\%) & $12(8.7)$ \\
Disorders, n (\%) & \\
Diabetes mellitus & $41(29.7)$ \\
Renal failure on dialysis & $15(10.9)$ \\
Hypertension & $87(63.0)$ \\
History of stroke & $30(21.7)$ \\
Chronic obstructive pulmonary disease & $15(10.9)$ \\
Peripheral vascular disease & $33(23.9)$ \\
Heart failure within 2 wk of surgery & $42(30.4)$ \\
Aortic root abscess & $138(100)$ \\
Severe aortic regurgitation & $67(48.5)$ \\
Preoperative sepsis & $3(2.2)$ \\
Preoperative pathogen, n (\%) & \\
Culture-negative & $6(4.3)$ \\
Staphylococcus aureus & $20(14.5)$ \\
Streptococcus species & $20(14.5)$ \\
Coagulase-negative Staphylococcus & $6(4.3)$ \\
Enterococcus species & $14(10.1)$ \\
Fungi & $5(3.6)$ \\
No culture data & $68(4.1)$ \\
\hline & \\
\hline
\end{tabular}

bleeding. Five patients (3.6\%) sustained a permanent stroke. Twenty-one patients $(15.2 \%)$ needed dialysis for postoperative renal failure, and $21(15.2 \%)$ had a permanent pacemaker implanted remote from the index procedure for complete heart block. No patient returned to the operating room for deep sternal wound infection. Chronic obstructive pulmonary disease, hypertension, and previous cerebrovascular accident were the strongest predictors of long-term mortality on multivariate analysis (Table 3). There were a total of 47 deaths $(34.1 \%)$ with a mean follow-up time of 2.4 years. Seventeen patients $(12.3 \%)$ died within 30 days; estimated 1-year mortality was $26.1 \%$ and estimated 5 -year mortality was $43.0 \%$.

\section{DISCUSSION}

Hospitalization for endocarditis has increased dramatically in recent years, and according to records from a database tracking hospital discharges in North Carolina, the incidence of hospital discharges for drug-related endocarditis has increased 12-fold (from 0.2 to 2.7 per 100,000 person-years) over a 6-year period. Over this corresponding
TABLE 2. Intraoperative and postoperative variables for patients with invasive endocarditis undergoing cryopreserved homograft replacement

\begin{tabular}{lc}
\hline \multicolumn{1}{c}{ Variable } & Value \\
\hline Number of patients & 138 \\
30-d mortality, $\mathrm{n}(\%)$ & $17(12.3)$ \\
\hline Cardiopulmonary bypass time, min, median (range) & $233(42.0-622)$ \\
Cross-clamp time, min, median (range) & $191(20-400)$ \\
\hline Concomitant mitral surgery, n (\%) & \\
$\quad$ Repair & $16(11.5)$ \\
$\quad$ Replacement & $7(5.0)$ \\
Initial ICU stay, h, median (range) & $79.0(1.0-1227)$ \\
Reoperation bleeding, $\mathrm{n}(\%)$ & $11(8.0)$ \\
Neurologic stroke, permanent, $\mathrm{n}(\%)$ & $5(3.6)$ \\
\hline New need for renal dialysis, $\mathrm{n}(\%)$ & $21(15.2)$ \\
Pacemaker, $\mathrm{n}(\%)$ & $21(15.2)$ \\
\hline Deep sternal wound infection, $\mathrm{n}(\%)$ & $0(0)$ \\
\hline Postoperative length of stay, d, median (range) & $10.0(0.0-127)$ \\
\hline
\end{tabular}

ICU, Intensive care unit.

time frame, there was an 18-fold increase in associated hospital costs, from \$1.1 million in 2010 to 22.2 million in 2015. ${ }^{18-20}$

Bearing in mind the increasing incidence of IVDArelated IE with concomitant hospital cost increases, the need for scrutiny of surgical practices, readmission for recurrence rates, IVDA recidivism, and outcomes analyses are critically important in efforts to contain this expanding national health care problem. We contend that the use of aortic homograft replacement for invasive aortic valve endocarditis allows for better debridement, durable reconstruction of the outflow tract and aortomitral continuity, a lower incidence of recurrence, and ultimately better cost containment. Several studies have demonstrated the cost-effectiveness of using cryopreserved aortic homografts as the primary surgical option for aortic endocarditis. ${ }^{21-23}$ Efficacy is also impacted by homograft resource availability, surgical proficiency with left ventricular outflow tract reconstruction and homograft implantation, and postoperative maintenance of patient IVDA abstinence.

We recommend that all patients presenting with IVDAassociated invasive IE undergo a multidisciplinary evaluation that includes a "social/health care contract" that outlines commitment to both physical and drug rehabilitation. All patients who present with native invasive aortic root abscess and have committed to postoperative rehabilitation are considered candidates for surgery unless demonstrated otherwise. However, patients who have demonstrated recidivism and present with recurrent IVDA-associated IE are scrutinized by the 
TABLE 3. Predictors of long-term mortality after the aortic root procedure with a homograft on univariable analysis

\begin{tabular}{lcc}
\hline \multicolumn{1}{c}{ Variable } & HR $(\mathbf{9 5} \% \mathbf{C I})$ & $\boldsymbol{P}$ value \\
\hline Age & $1.00(0.97-1.01)$ & .559 \\
Male sex & $1.28(0.61-2.65)$ & .507 \\
Hypertension & $1.33(0.71-2.47)$ & .366 \\
Congestive heart failure & $1.69(0.92-3.09)$ & .085 \\
COPD & $1.62(0.71-3.68)$ & .244 \\
Previous stroke/TIA & $0.68(0.34-1.34)$ & .261 \\
Previous renal failure & $1.39(0.62-3.12)$ & .421 \\
Postoperative stroke/TIA & $0.49(0.06-3.59)$ & .485 \\
Reoperation for bleeding & $1.55(0.64-3.74)$ & .326 \\
Prolonged ventilation & $2.18(1.10-4.30)$ & .024 \\
\hline
\end{tabular}

$H R$, Hazard ratio; $C I$, confidence interval; $C O P D$, chronic obstructive pulmonary disease; TIA, transient ischemic attack.

multidisciplinary team, and reoperative intervention is embarked upon only in the presence of appropriate signs and measures indicative of long-term success. The multidisciplinary approach is of paramount importance for patients who have demonstrated recidivism. Specifically, specialists in psychiatry, infectious disease, nursing, and rehabilitation along with the surgical team meet with the patient and family to explore the reasons behind recidivism and evaluate whether the patient and family can make a commitment to drug rehabilitation. Without an explicit commitment to rehabilitation from patients with recent recidivism, reoperative aortic root surgery might not provide a long-term benefit.

There is a paucity of contemporary data available on the use of homografts for IVDA-associated endocarditis. Musci and colleagues ${ }^{24}$ reported their experience over a 21-year period with 221 patients who underwent homograft aortic root replacement for 122 cases of prosthetic valve endocarditis and 99 cases of native valve endocarditis. Native valve endocarditis survival following homograft placement was $83.3 \%$ at 30 days, $76.6 \%$ at 1 year, and $66.5 \%$ at 5 years. Postoperative survival for prosthetic valve endocarditis was significantly worse, at $74.6 \%$ at 30 days, $67.1 \%$ at 1 year, and $48.1 \%$ at 5 years. Thirty-one patients $(14 \%)$ required reoperation for either recurrent endocarditis or structural valve degeneration. Not surprisingly, reoperation occurred more frequently in patients under age 40 years. Sabik and colleagues ${ }^{25}$ reported on a series of 103 homograft root replacements for endocarditis between 1988 and 2000, in which $78 \%$ of the patients had aortic root abscess. Hospital mortality was low at $3.9 \%$, and survival was $90 \%$ at 1 year, $86 \%$ at 2 years, $73 \%$ at 5 years, and $56 \%$ at 10 years. Of note, unlike our series (all patients with aortic root abscess), only $78 \%$ of the patients in that study had an aortic root abscess. Preventza and colleagues ${ }^{16}$ reported 29 homograft root replacements for IE with an operative mortality of
$10.3 \%$. During a median follow-up period of 2.5 years, survival was $65.7 \%$. Similarly, in our series of high-risk, mostly reoperative aortic root surgeries, late survival was $65.9 \%$, with a mean follow-up of 2.4 years.

The role of aggressive debridement and root replacement rather than simple aortic valve replacement (AVR) in cases of invasive IE cannot be overstated. A recent meta-analysis by Chen and colleagues ${ }^{26}$ identified a $50 \%$ reduction in the risk of reoperation within 1 year for those patients who underwent aortic root replacement compared with those who underwent AVR. There are no large series comparing long-term patch repair and aortic root replacement in this scenario. Although the primary goal of surgery involving IE is to have a safe outcome, equally important is to ensure freedom from infection and reoperation in these patients. Simple AVR or a patch repair of the sinus segment with AVR in the setting of IE with a root abscess may not be sufficient to eliminate risk of recurrent endocarditis. Many of these patients are young and will require reoperations for structural valve degeneration throughout life. An additional operation in the short term for recurrence of infection/prosthetic valve endocarditis is likely to increase the risk of morbidity and mortality in the short term and may potentially affect recovery in rehabilitation. The reported incidence of reinfection following aortic homograft replacement is acceptably low, ranging from $0.0 \%$ to $6.8 \%{ }^{23,24,27-29}$ Perrotta and colleagues ${ }^{29}$ reported a significantly higher incidence of recurrent endocarditis following the initial operation in patients treated with a prosthetic valve compared with those treated with a homograft $(12.9 \%$ vs $0.0 \%)$.

Although historically relevant reports have previously indicated enthusiasm for the homograft as the optimal replacement option for aortic IE, recent studies do not consistently embrace this perspective. ${ }^{30,31}$ For example, in a 10-year series of 134 patients who underwent aortic root replacement for active endocarditis, Jassar and colleagues ${ }^{30}$ found no significant differences in major complications or in-hospital mortality when comparing mechanical composite graft, biological valved conduit, and homograft root replacement. Notably, there were similar rates of reoperation, reinfection, and readmission across the 3 groups. The authors concluded that complete eradication of infected tissue was more important than conduit choice in determining outcomes. However, that study did not take into account the distinct presence of aortic annular abscess, as in our present series, for which a homograft may have distinct advantages. To better accommodate the reconstruction required after aggressive debridement of annulus and outflow tract, aortic root homograft conduits include the aortomitral continuity, anterior leaflet of the mitral valve, and muscular component of the left ventricular outflow tract. These additional tissues are available for use in reconstruction en bloc with aortic root replacement when using a 
homograft. In addition, the redundant biological tissue at the base of the conduit allows for the filling of dead space, which prosthetic stented or stentless conduits cannot. The flexibility of these homografts for accommodating the debrided bed domain compared with a rigid prosthesis allows for a much more forgiving reconstruction-always to normal, healthy tissue following wide debridement. It is important to note that reoperative complex aortic root operations can be challenging in this setting, and a deep knowledge of structures and pitfalls around the aortic root is critical. $^{32}$

Both homografts and stentless porcine aortic roots have been shown to have a more favorable hemodynamic profile that gives rise to lower aortic mean gradients, improved left ventricular mass regression, and improved ejection fraction. ${ }^{33,34}$ Many of the patients undergoing homograft aortic root replacement for IE are young and will require reoperation for valve calcification and/or degeneration. ${ }^{35-37}$ In older patients, valve-in-valve transcatheter AVR has been attempted in patients with valved homografts with reasonable success. ${ }^{38}$ Despite this apparent drawback of valve degeneration, the benefit derived with respect to infection control and mitigation of IE-related mortality effectively outweighs the long-term risk. Moreover, we demonstrate that an estimated $43 \%$ of this high-risk population will not survive beyond 5 years. Beyond assessing the risks of subsequent reintervention, prevention of IVDA recidivism becomes paramount to improving long-term survival.

This study is limited by the typical constraints of a retrospective study design. We did not propensity-match our patients, and thus there may be a component of the outcomes confounded by preexisting comorbidities. We do not have complete follow-up on the postoperative IVDA status of our patients.

\section{CONCLUSIONS}

Cryopreserved homograft replacement is a safe and desirable option for high-risk patients with invasive IE and aortic root abscess. Homograft accommodation for a widely debrided aortic annular bed has fundamental advantages over other valve replacement options.

\section{Conflict of Interest Statement}

Authors have nothing to disclose with regard to commercial support.

\section{References}

1. Slipczuk L, Codolosa JN, Davila CD, Romero-Corral A, Yun J, Pressman GS, et al. Infective endocarditis over the past five decades: a systematic review. PLoS One. 2013;8:e82665.

2. Holland TL, Baddour LM, Bayer AS, Hoen B, Miro JM, Fowler VG Jr. Infective endocarditis. Nat Rev Dis Primers. 2016;2:16059.

3. Baddour LM, Wilson WR, Bayer AS, Fowler VG Jr, Tleyjeh IM, Rybak MJ, et al. Infective endocarditis in adults: diagnosis, antimicrobial therapy, and management of complications: a scientific statement for healthcare professionals from the American Heart Association. Circulation. 2015;132:1435-86.
4. Pant S, Patel NJ, Deshmukh A, Golwala H, Patel N, Badheka A, et al. Trends in infective endocarditis incidence, microbiology, and valve replacement in the United States from 2000 to 2011. J Am Coll Cardiol. 2015;65:2070-6.

5. Anguera I, Miro JM, San Roman JA, de Alarcon A, Anguita M, Almirante B, et al. Periannular complications in infective endocarditis involving prosthetic aortic valves. Am J Cardiol. 2006;98:1261-8.

6. Wang A, Pappas P, Anstrom KJ, Abrutyn E, Fowler VG Jr, Hoen B, et al. The use and effect of surgical therapy for prosthetic valve infective endocarditis: a propensity analysis of a multicenter, international cohort. Am Heart J. 2005;150: 1086-91.

7. Foghsgaard S, Bruun N, Kjaergard H. Outcome of aortic homograft implantation in 24 cases of severe infective endocarditis. Scand J Infect Dis. 2008;40:216-20.

8. Svensson LG, Adams DH, Bonow RO, Kouchoukos NT, Miller CD, O'Gara PT, et al. Aortic valve and ascending aorta guidelines for management and quality measures. Ann Thorac Surg. 2013;95(6 Suppl):S1-66.

9. Stelzer P, Varghese R, Stelzer P, Stelzer Varghese R, Paul, Varghese Robin. Stentless aortic valve and root replacement. In: Cohn LH, Adams DH, Cohn LH Adams DH, eds. Cardiac Surgery in the Adult. 5th ed. New York, NY: McGraw-Hill; 2018.

10. Keeshin SW, Feinberg J. Endocarditis as a marker for new epidemics of injection drug use. Am J Med Sci. 2016;352:609-14.

11. Bouza E, Menasalvas A, Muñoz P, Vasallo FJ, del Mar Moreno M, García Fernández MA. Infective endocarditis - a prospective study at the end of the twentieth century: new predisposing conditions, new etiologic agents, and still a high mortality. Medicine (Baltimore). 2001;80:298-307.

12. Hogevik H, Olaison L, Anderson R, Lindberg J, Alestig K. Epidemiological as pects of infective endocarditis in an urban population. A 5-year prospective study. Medicine (Baltimore). 1995;74:324-39.

13. Wurcel AG, Anderson JE, Chui KK, Skinner S, Knox TA, Snydman DR, et al Increasing infectious endocarditis admissions among young people who inject drugs. Open Forum Infect Dis. 2016;3: ofw157.

14. Ferraris VA, Sekela ME. Missing the forest for the trees: the world around us and surgical treatment of endocarditis. J Thorac Cardiovasc Surg. 2016;152:677-80.

15. Kim JB, Ejiofor JI, Yammine M, Ando M, Camuso JM, Youngster I, et al. Surgical outcomes of infective endocarditis among intravenous drug users. J Thorac Cardiovasc Surg. 2016;152:832-41.e1.

16. Preventza O, Mohamed AS, Cooley D, Rodriguez V, Bakaeen FG, Cornwell LD, et al. Homograft use in reoperative aortic root and proximal aortic surgery for endocarditis: a 12-year experience in high-risk patients. J Thorac Cardiovasc Surg. 2014;148:989-94.

17. Sultan I, Seese L, Lagazzi L, Gleason TG. Concomitant aortic valve replacemen with orthotopic heart transplantation. J Thorac Cardiovasc Surg. 2018;155: e151-2.

18. Center for Behavioral Health Statistics and Quality. Behavioral Health Trends in the United States: Results from the 2014 National Survey on Drug Use and Health. HHS publication SMA 15-4927. Rockville, MD: US Department of Health and Human Services; 2015.

19. Wallen TJ, Szeto W, William M, Atluri P, Arnaoutakis G, Fults M, et al. Tricuspid valve endocarditis in the era of the opioid epidemic. $J$ Card Surg. 2018;33:260-4.

20. Fleischauer AT, Ruhl L, Rhea S, Barnes E. Hospitalizations for endocarditis and associated health care costs among persons with diagnosed drug dependence — North Carolina, 2010-2015. MMWR Morb Mortal Wkly Rep. 2017; 66:569-73.

21. Vuran C, Simon P, Wollenek G, Ozker E, Aslım E. Midterm results of aortic valve replacement with cryopreserved homografts. Balkan Med J. 2012;29:170-3.

22. Talwar S, Mohapatra R, Saxena A, Singh R, Kumar AS. Aortic homograft: a suit able substitute for aortic valve replacement. Ann Thorac Surg. 2005;80:832-8.

23. Yaghoubi M, Aghayan HR, Arjmand B, Emami-Razavi SH. Cost-effectiveness of homograft heart valve replacement surgery: an introductory study. Cell Tissue Bank. 2011;12:153-8.

24. Musci M, Weng Y, Hübler M, Amiri A, Pasic M, Kosky S, et al. Homograft aortic root replacement in native or prosthetic active infective endocarditis: twenty-year single-center experience. J Thorac Cardiovasc Surg. 2010;139:665-73.

25. Sabik JF, Lytle BW, Blackstone EH, Marullo AG, Pettersson GB, Cosgrove DM Aortic root replacement with cryopreserved allograft for prosthetic valve endocarditis. Ann Thorac Surg. 2002;74:650-9; discussion: 659.

26. Chen GJ, Lo WC, Tseng HW, Pan SC, Chen YS, Chang SC. Outcome of surgica intervention for aortic root abscess: a meta-analysis. Eur J Cardiothorac Surg. 2018:53:807-14. 
27. Perrotta S, Aljassim O, Jeppsson A, Bech-Hanssen O, Svensson G. Survival and quality of life after aortic root replacement with homografts in acute endocarditis. Ann Thorac Surg. 2010;90:1862-7.

28. Perrotta S, Zubrytska Y. Valve selection in aortic valve endocarditis. Kardiochir Torakochirurgia Pol. 2016;13:203-9.

29. Perrotta S, Jeppsson A, Fröjd V, Svensson G. Surgical treatment of aortic prosthetic valve endocarditis: a 20-year single-center experience. Ann Thorac Surg. 2016;101:1426-32.

30. Jassar AS, Bavaria JE, Szeto WY, Moeller PJ, Maniaci J, Milewski RK, et al. Graft selection for aortic root replacement in complex active endocarditis: does it matter? Ann Thorac Surg. 2012;93:480-7.

31. David TE, Gavra G, Feindel CM, Regesta T, Armstrong S, Maganti MD. Surgical treatment of active infective endocarditis: a continued challenge. J Thorac Cardiovasc Surg. 2007;133:144-9.

32. Sultan I, Komlo CM, Bavaria JE. How I teach a valve-sparing root replacement. Ann Thorac Surg. 2016;101:422-5.

33. Basarir S, Islamoglu F, Ozkisacik E, Atay Y, Boga M, Bakalim T, et al. Comparative analysis of left ventricular hemodynamics and hypertrophy after aortic valve replacement with homografts or mechanical valves. $J$ Heart Valve Dis. 2000;9:45-52.
34. Kunadian B, Vijayalakshmi K, Thornley AR, de Belder MA, Hunter S, Kendall S, et al. Meta-analysis of valve hemodynamics and left ventricular mass regression for stentless versus stented aortic valves. Ann Thorac Surg. 2007;84:73-8.

35. Ejiofor JI, Byrne JG, Leacche M. Reoperative valve surgery. In: Cohn LH, Adams DH, eds. Cardiac Surgery in the Adult. 5th ed. New York, NY: McGraw-Hill; 2018.

36. Hasnat K, Birks EJ, Liddicoat J, Hon JK, Edwards S, Glennon S, et al. Patient outcome and valve performance following a second aortic valve homograft replacement. Circulation. 1999;100(19 Suppl):II42-7.

37. McGiffin DC, Galbraith AJ, O'Brien MF, McLachlan GJ, Naftel DC, Adams P, et al. An analysis of valve re-replacement after aortic valve replacement with biologic devices. J Thorac Cardiovasc Surg. 1997;113:311-8.

38. Sultan I, Siki M, Wallen T, Szeto W, Vallabhajosyula P. Management of coronary obstruction following transcatheter aortic valve replacement. J Card Surg. 2017; $32: 777-81$

Key Words: aortic root abscess, aortic root replacement, endocarditis, homograft 